\title{
UNIVERSITY OF GALIFORNIA PUBLICATIONS IN \\ AMERICAN ARCHAEOLOGY AND ETHNOLOGY
}

VOLUME XLV

\author{
EDITORS \\ R. H. LowIE \\ E. W. GIFFORD \\ D. G. Mandelbaum \\ R. L. OLSON
}

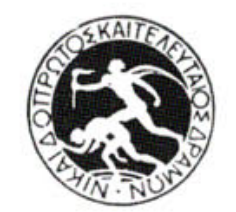





\title{
THE TUKUNA
}

\author{
BY \\ CURT NIMUENDAJÚ \\ Edited by \\ ROBERT H. LOWIE
}

Translated by

WILLIAM D. HOHENTHAL 


\title{
University of Camifornia Publications in Ambrican Archaeology and Ethnology
}

EdToRs (BERKELEY) : R. H. LowIE, E. W. GifTord, D. G. MANDELBAUM, R. L. OlsoN Volume 45, pp. ix + 1-210, plates 1-18, 13 figures in text, 1 map

Submitted by editors: June 5, 1950

Issued April 16, 1952

Price, Paper, $\$ 3.50$; Cloth, $\$ 4.25$

\author{
University of California Press \\ BERKELEY AND LOS ANGELES \\ Cammornia \\ $\prec$ \\ Cambridge University Press \\ LONDON, ENGLAND
}

